\title{
Psychological Facilitation of Residence Hall Students
}

Svetlana Yu. Zhdanova, Anna V. Pecherkina, Lina Z. Zaripova, Tatyana A. Popova, Liubava O. Puzureva

Department of Developmental Psychology, Perm State National Research University, Russian Federation

\section{Introduction}

Studies show that one of the problems faced by students in the process of studying at a university is the problem of adapting students to new conditions of the educational environment. This problem becomes especially relevant for students living in residence halls, since the process of adaptation to new conditions of educational space may be fraught with difficulties for them in adapting to new living conditions. According to I.A. Bayeva, students living in residence halls undergo a double adaptation. On the one hand, students experience difficulties in adapting to new learning conditions at the university (new requirements; academic forms; new students' group), on the other hand, they have to adapt to new living conditions.

Psychological assistance and facilitation of students living in residence halls includes the study of factors contributing to the psychological safety of the personality; investigating the adaptation to a new place of residence, as well as the search for psychological resources aimed at overcoming adverse conditions.

\section{Purpose of the study}

In order to improve the living conditions in student residence hall, we organized and conducted a special study. In accordance with the request, the purpose and objectives of the study were formulated:

1) identify the factors that prevent comfortable living of students in the residence hall;

2) explore possible solutions to the problems faced by students in the process of living in a residence hall.
Methods

$>$ The study was implemented on the basis of the Perm State University. 140 students took part in the study.

The self-report questionnaire was developed for the study. The questionnaire included 44 questions. It was designed based on the concept of $A$. Maslow about the hierarchy of needs; the of I.A. Mesharikova, E.N. Pogodina approach to study the causes, the dynamics of conflicts that arise between students living in residence hall; the approach of A.V. Lubin to the study of living conditionsz. The following analysis criteria were used as key parameters: conflict frequency; conflict participants; causes of conflict; ways of social support (who helps living in a residence hall in case of a conflic situation); possible ways to overcome conflict situations; the degree of satisfaction of the needs of students living in residence hall.

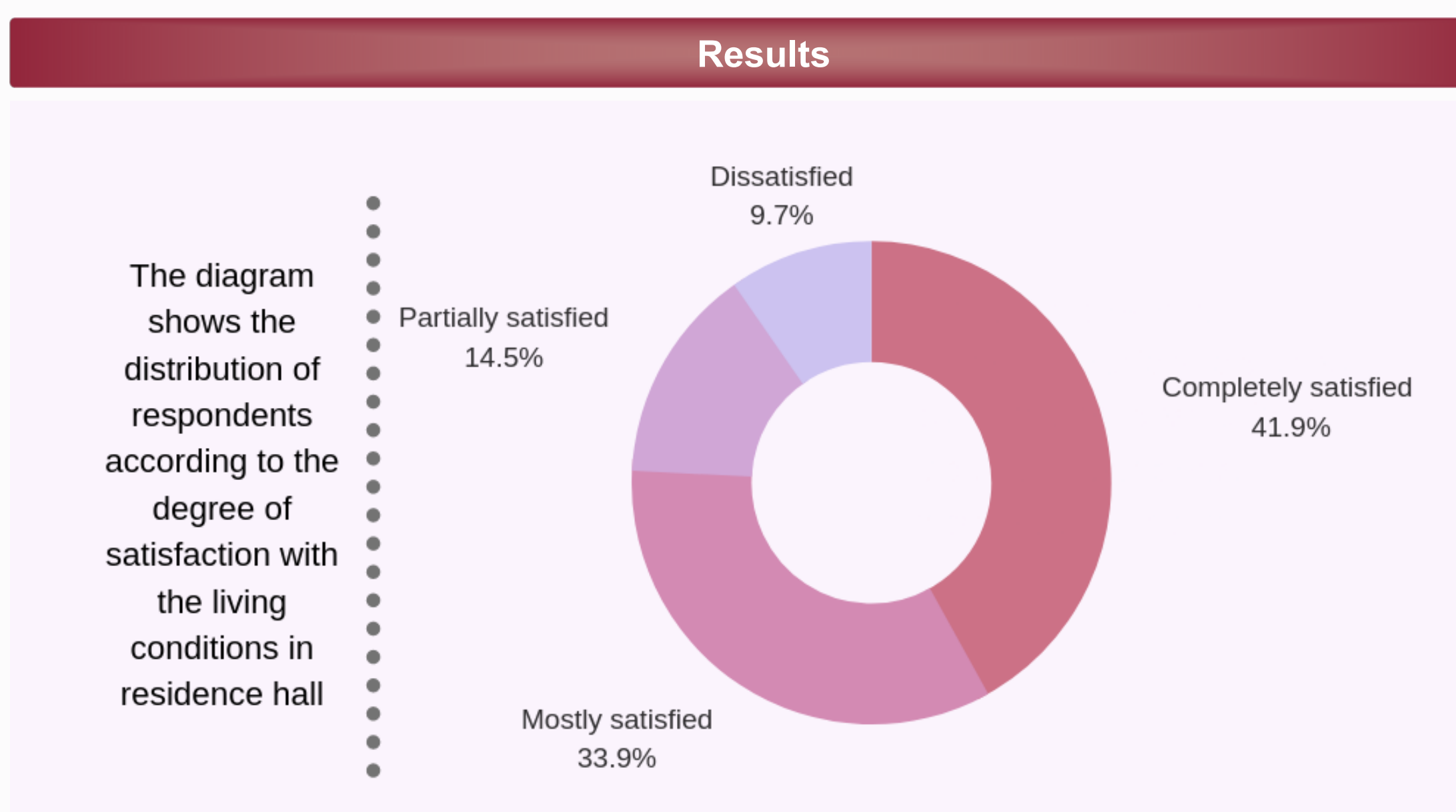

As problem areas, students note the organization of space in common areas (showers, toilet, kitchen). Students talk about the need for repairs, they also add that the furniture in the rooms is quite old. The acute problem for students is access control, which sets stringent requirements when returning to the residence hall at night. In accordance with this rule, the student cannot leave the residence hall at night. In this predicament students who are forced to work (delay in work) will fall. This fact is consistent with data from other researchers, in particular, A.V. Lyubina, who points to this problem, writes that "any valid reasons (delay at work, visiting holidays, personal life) are not taken into account, on the contrary, it becomes a reason for putting pressure on a student. Apparently, this can explain the fact that, in $49 \%$ of cases the conflicts were forced by watchmen, only in $14,3 \%$ of cases - conflicts arise with roommates.
On the positive side, students and undergraduates point out "a low living costs a the hall; an atmosphere that smoothes out everyday problems; the ability to communicate with people; cleaning the dormitory on weekdays; students' understanding; level of security; the ability to receive guests; availability of all amenities; Internet access; team cohesion".

Conclusions

1. The research results indicate that for students living in a residence hall, basic, natural needs related to living conditions in a residence hall, as well as the need for recognition and respect, are relevant.

2. It is valuable that students could observe ways to overcome existing difficulties. For instance, students propose to improve the feedback system, use in the hall a mechanism for implementing student initiatives and encouraging them as a possible way to solve problems in the residence hall.

3. Psychological assistance and accompaniment to persons living in a residence hall includes the study of factors contributing to the psychological security of students' personality, their adaptation to a new place of residence, the search for psychological resources aimed at overcoming unfavorable conditions.

4. As a result of the study, resources aimed at mproving the living conditions in the student residence hall were identified. There were personal and environmental resources. Personal resources nclude coping strategies to successfully cope with difficult life situations. External factors associated with the organization of the material, living and communicative space are considered as environmental resources.

www.psu.ru 